\title{
Provinces reject federal call for prosecution of over-prescribing physicians
}

$\mathrm{P}$ olicing the over-prescription of opioids is a matter best left to local jurisdictions and there's absolutely no need for intrusive federal measures to limit the authority of some physicians to prescribe such drugs, several provinces say.

The provinces add that their existing oversight systems are effectively constraining suspect prescribing patterns by physicians and abuse of pain-relieving medications. In British Columbia, for example, "we feel that our system has a number of protections built into it that limit abuse of narcotics like oxycodone, and we are confident in the work of our college [of physician and surgeons] to investigate any concerns raised with them," says Ryan Jabs, spokesman for the province's health ministry.

The provinces also uniformly rejected Health Minister Leona Aglukkaq's controversial offer to step into the opioid fray to crack down on over-prescribing physicians in those provinces that aren't up to the task and are willing to cede jurisdiction to the federal government (www.cmaj.ca/site /earlyreleases/4theRecord.xhtml).

Nor do they appear inclined to forward names of overprescribing physicians to the federal government for prosecution.

"We haven't forwarded any cases to Health Canada," says Doug Spitzig, manager of the prescription review program at the College of Physicians and Surgeons of Saskatchewan. "We have better capacity of dealing with the overprescribing than the feds do."

Saskatchewan does not appear to be the exception as Health Canada indicates that no province has taken up Aglukkaq's highly political offer, which was clearly part of a bid to deflect attention from the federal decision not to ban the production of generic forms of oxycodone (www.cmaj.ca/lookup/doi/10 .1503/cmaj.109-4326).

The Controlled Substances and Tobacco Directorate has not received a

provincial drug plans to align our approaches as much as possible with respect to generic OxyContin. In particular, the Atlantic provincial drug plans are reviewing the benefit status of all opioids to help ensure appropriate access and use," says Mélanie Sivret, spokesperson for the Department of Health.

Similarly, the Northwest Territories indicates that it is examining mechanisms to limit access to addictive substances. "We think this can be achieved by improving measures to ensure that the drugs are provided only to patients with valid medical need for them," says Damien Healy, spokesperson for province's department of health and social services. "Additionally, we are taking steps to improve support to our clinicians at the front line to make sure that

single report from a province over the past year identifying an instance of overprescribing of oxycodone, Stéphane Shank, senior media relations advisor for Health Canada, writes in an email.

Ontario says there's no need for federal involvement in the monitoring of opioid prescriptions or the prosecution of over-prescribers. "The federal intervention we need is to ban generic OxyContin," says Zita Astravas, spokesperson for the Ontario Ministry of Health and Long-Term Care.

Alberta, similarly, says inappropriate prescribing of oxycodone is an issue best addressed in-house. "Prescribing practices are really a CPSA [College of Physicians and Surgeons of Alberta] issue," Howard May, a spokesman for Alberta Health, writes in an email.

Other provinces, meanwhile, indicate that they are investigating alternative means of constraining the availability of opioids. New Brunswick, for example, is "working with the other federal and they have access to guidance on best practice in the area of pain management."

Rather than prosecuting overprescribing physicians, the provinces also say their primary response to the problem is to attempt to educate doctors about appropriate use of painkillers.

In $\mathrm{BC}$, for example, the College of Physicians and Surgeons of British Columbia is working with roughly 200 physicians, at any given time, using an "education intervention" model that lasts about two years.

"These are not bad doctors. They benefit from our educational intervention and so do their patients," says Dr. Galt Wilson, deputy registrar for the College of Physicians and Surgeons of British Columbia. "The solution is an educational one. We take our responsibility to educate and remediate physicians very seriously and make a significant investment in it." - Adam Miller, CMAJ 